\title{
Review Paper: Therapeutic Strategies in Managing Acute Paraquat Poisoning: A Review Study
}

\author{
Mohammad Majidi ${ }^{*}$
}

1. Department of Forensic Medicine and Clinical Toxicology, School of Medicine, Urmia University of Medical Sciences, Urmia, Iran.

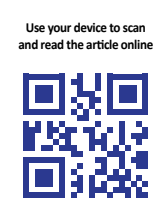

Citation: Majidi M. Therapeutic Strategies in Managing Acute Paraquat Poisoning: A Review Study. International Journal of Medical Toxicology and Forensic Medicine. 2021; 11(3):33633. https://doi.org/10.32598/ijmtfm.v11i3.33633

https://doi.org/10.32598/ijmtfm.v11i3.33633

(c) 0

Article info:

Received: 7 Jan 2021

First Revision: 11 Jan 2021

Accepted: 13 Jan 2021

Published: 19 Oct 2021

\section{Keywords:}

Herbicides, Paraquat, Poisoning, Therapeutics

\section{A B S TRACT}

Background: Paraquat is an extremely toxic herbicide that causes such severe adverse effects as acute lung injury, pulmonary fibrosis, metabolic acidosis, cardiogenic shock, acute renal failure, and even death. Regarding the high prevalence and mortality rate without a specific antidote in paraquat poisoning, we explored managing acute paraquat poisoning.

Methods: In this study, required articles were searched using the following keywords: "paraquat poisoning" and "treatment" on an electronic database, such as Pubmed and Google Scholar from January 2013 to December 2020.

Results: This article examined pharmacokinetic, clinical, and laboratory findings, complications, diagnosis, prognostic factors, and the treatment of paraquat poisoning. Then, the medical management and therapeutic procedures of paraquat poisoning were discussed.

Conclusion: Although there exists no antidote for paraquat poisoning, numerous therapeutic methods have been suggested for treating paraquat poisoning. However, their efficacy remains undiscovered.

An interesting finding in one study indicating that endotracheal intubation is an inappropriate procedure for managing paraquat poisoning; further studies are required in this regard. For these reasons, preventing poisoning and using other herbicides with less toxicity than paraquat are recommended.

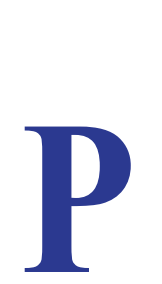

\section{Introduction}

oisoning due to pesticide usually occurs intentionally, with suicidal ideations; in some cases, it occurs accidentally, and rarely occurs criminally [1]. Paraquat poisoning was recognized in rodents since the early 1960s. Since then, it is consumed in numerous agricultural countries [2]. Recent studies indicated that the mortality rate of pesticide poisoning was approximately 250000 to 370000 cases, annually. Additionally, the annual incidence of paraquat poisoning was $\geq 3.8$ cases/100000 inhabitants/year [3, 4]. Paraquat is a highly toxic, non-selective, and dose-dependent herbicide.

\footnotetext{
* Corresponding Author:

Mohammad Majidi, MD

Address: Department of Forensic Medicine and Clinical Toxicology, School of Medicine, Urmia University of Medical Sciences, Urmia, Iran. Tel: +98 (914) 3472825

E-mail:majidi_m@umsu.ac.ir
} 
According to studies, suicide attempts with herbicides, like paraquat has become highly frequent in developing agriculture countries due to their availability and costeffectiveness in individuals [5-8]. The main route of the involvement of paraquat poisoning is through the mouth [8]. Furthermore, the absorption of paraquat poisoning has been reported through other routes, such as dermal, mucus, and inhalation contacts [5].

Unlike some developing countries and due to high mortality, the production and distribution of paraquat have been stopped in the United States and the European Union since 1994 and 2007, respectively [5, 6]. Studies revealed that the minimum lethal dose of paraquat poisoning for adults equals $20-30 \mathrm{mg} / \mathrm{kg}$. Besides, studies suggested that the lethal doses of paraquat poisoning are $20 \mathrm{~mL}$ of a $20 \%$ solution [8-11]. Mortality is very high in all centers, despite numerous improvements in treatment; however, the mortality rate varies from $50 \%$ to $90 \%$. Especially in cases of an intentional poisoning with concentrated formulation, the mortality rate is $100 \%$ [5]. This review study was conducted given the importance of the topic and high mortality rate despite no antidote for paraquat poisoning.

\section{Type of study}

In this article, the pharmacokinetics, such as the mechanism of toxicity, clinical and laboratory findings, complications, as well as the diagnosis and prognosis factors of paraquat poisoning were studied. Then, medical management and therapeutic procedures in paraquat poisoning were discussed.

\section{Evidence acquisition}

In this study, required articles using the keywords "paraquat poisoning" and "treatment" were searched on electrical databases, such as Pubmed and Google Scholar from January 2013 to December 2020.

\section{Discussion}

Pharmacokinetic (the absorption, distribution, and mechanism) of toxicity

The main routes of the absorption of paraquat poisoning are through the mouth, skin, mucus, and respiratory system $[5,8]$. The absorption of paraquat is very rapid and its maximum concentration occurs within one-hour post-ingestion. The oral bioavailability of paraquat in humans is $<5 \%$. Moreover, the half-life of the distribution is estimated at approximately 5 hours. Paraquat minimally binds to plasma proteins and is often rapidly distributed in all tissues. The maximum time for diagnosis of plasma paraquat is about 48 hours; however, it can be detected in urine for $>30$ days in surviving patients. With normal kidneys, $90 \%$ of paraquat is eliminated in the first 24 hours of intoxication; however, with acute renal failure, it is prolonged to more than 48 to 80 hours [12]. Paraquat can inhibit the reduction of $\mathrm{NAD}(\mathrm{P})+$ to $\mathrm{NAD}(\mathrm{P}) \mathrm{H}$, which produces oxygen radicals and inflammatory responses, resulting in cell damage, multiple organ failures, and even death. The mechanisms of action of paraquat poisoning are presented in Figure 1.

\section{Clinical and laboratory findlings and complications}

The main clinical symptoms and signs of paraquat poisoning include nausea, vomiting, epigastric pain, mucosal lesions, inflammation of the oral cavity and pharynx, mild to moderate loss of consciousness, and fever. Moreover, the main laboratory findings include leukocytosis, anemia, acute hepatitis with the rise of alanine transaminase and aspartate transaminase, increased serum bilirubin, and creatinine [5, 14]. Significant complications of paraquat poisoning are pulmonary, cardiovascular, hepatic, renal, coagulation, and fibrinolysis dysfunctions due to cell damage $[11,15,16]$. Additionally, progressive lung injury and acute renal failure are the main causes of death in paraquat poisoning $[11,16]$.

\section{Diagnosis}

The diagnosis of paraquat poisoning is usually based on clinical suspicions; however, measuring blood level concentration and urine screen tests are used to confirm the diagnosis of paraquat poisoning $[1,11]$. The evaluation of urinary paraquat (the level of urinary sodium dithionite) cannot accurately predict the outcome of paraquat poisoning in patients. However, in one study, patients with paraquat poisoning who had urinary paraquat concentration about 25-50 ppm (or especially above $50 \mathrm{ppm}$ ) after 24 hours of consumption experienced a mortality rate of about $90 \%$. Serum or plasma paraquat levels are measured by various methods, including high-performance liquid chromatography (HPLC), gas chromatography-mass spectrometry (GC-MS), enzymelinked immunosorbent assay (ELISA), and spectrophotometry. Serum or plasma paraquat levels are also used to assess the prognosis of paraquat poisoning. One study revealed that plasma paraquat concentrations less than 2 ppm within 10 hours of intoxication indicated a good prognosis; however, this study was not supported in subsequent studies [15]. 


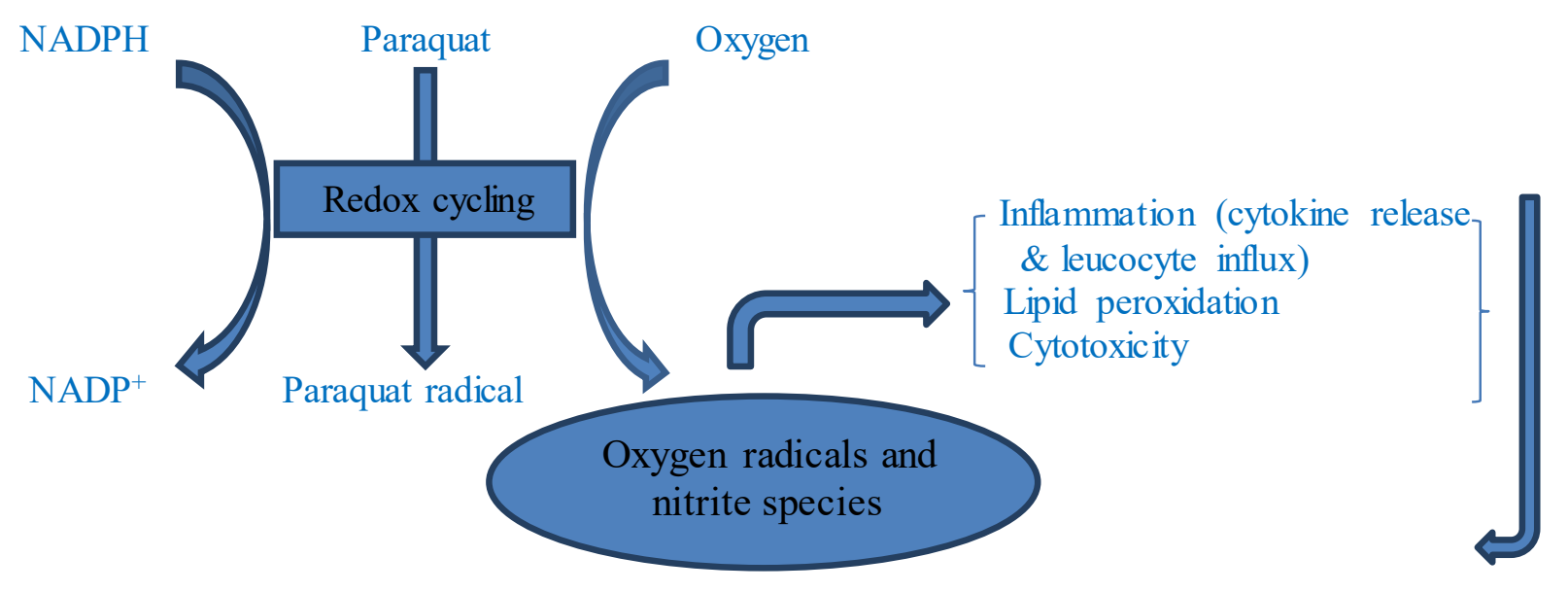

Multi organ damage and lung fibrosis

Figure 1. The mechanisms of action of paraquat poisoning $[6,12,13]$ International Journal of
Medical Toxicology \& forensic Medicine

\section{Prognostic factors}

Laboratory profiles and their effects on the prognosis of patients with paraquat poisoning were reported in limited studies $[11,16,17]$. Some studies demonstrated that increased leukocyte, prothrombin rate, the blood, and urine concentration of creatinine, pancreatic enzymes, and arterial lactate had a poor prognosis in paraquat poisoning $[10,11]$. Moreover, other predictors of prognosis in paraquat poisoning include APACHE II1 and SOFA2 [11].

\section{Treatment}

Paraquat poisoning has no specific antidote; however, previous studies suggested some treatment approaches that can be effective in the management of paraquat poisoning. Recent proposed treatments and procedures of paraquat poisoning are presented in Table 1 . Wu et al. (2018) in a prospective and observational clinical study evaluated 68 hospitalized patients with respiratory failure due to paraquat poisoning in Taiwan [18]. Then, a comparison was made between the do-notintubate group and endotracheal intubated group; they unexpectedly concluded that the procedure of intubation in paraquat poisoning can be considered inappropriate treatment [18].

\section{Conclusion}

There exists no antidote for paraquat poisoning; however,numerous therapeutic strategies have been suggested for managing paraquat poisoning . The mecha- nisms of multi-organ failure, especially lung injury and the pulmonary fibrosis of paraquat poisoning are cell damage caused by oxygen radicals and inflammatory cytokines (Interleukin-1 $\beta$ (IL-1 $\beta$ ), interleukin -6 (IL-6), and tumor necrosis factor-alpha (TNF- $\alpha)$ ). Therefore, most proposed treatment methods are based on antiinflammatory and anti-oxidative therapy. In addition, decreased absorption increased elimination of paraquat, and using procedures, such as extracorporeal and surgical procedures remain the main management methods of paraquat poisoning. However, their efficacy remains unestablished . Unexpectedly, a study suggested that endotracheal intubation is an inappropriate procedure for the management of paraquat poisoning. Thus, the prevention of poisoning and using other herbicides with less toxicity than paraquat is recommended.

\section{Ethical Considerations}

\section{Compliance with ethical guidelines}

All ethical principles were considered in this article.

Funding

This article was supported by the Urmia University of Medical Science.

\section{Author's contributions}

The main author contributed to preparing this article. 
Table 1. Proposed treatments and the procedures of paraquat poisoning and their mechanisms of action

\begin{tabular}{ll}
\hline Mechanisms of Action & Recent Treatment Methods \\
\hline Supportive therapy [11, 19] & $\begin{array}{c}\text { Fluid infusion and pulmonary supports [19] } \\
\text { Parenteral nutrition [11] }\end{array}$ \\
Reduce absorption [19-22] & $\begin{array}{c}\text { Gastric lavage and the ingestion of charcoal [19] } \\
\text { Lavage with sucralfate [20] }\end{array}$ \\
Milk gargle and activated carbon retention enema [21]
\end{tabular}

Eliminate and reduced absorption of paraquat

[23]

Rhubarb [23]

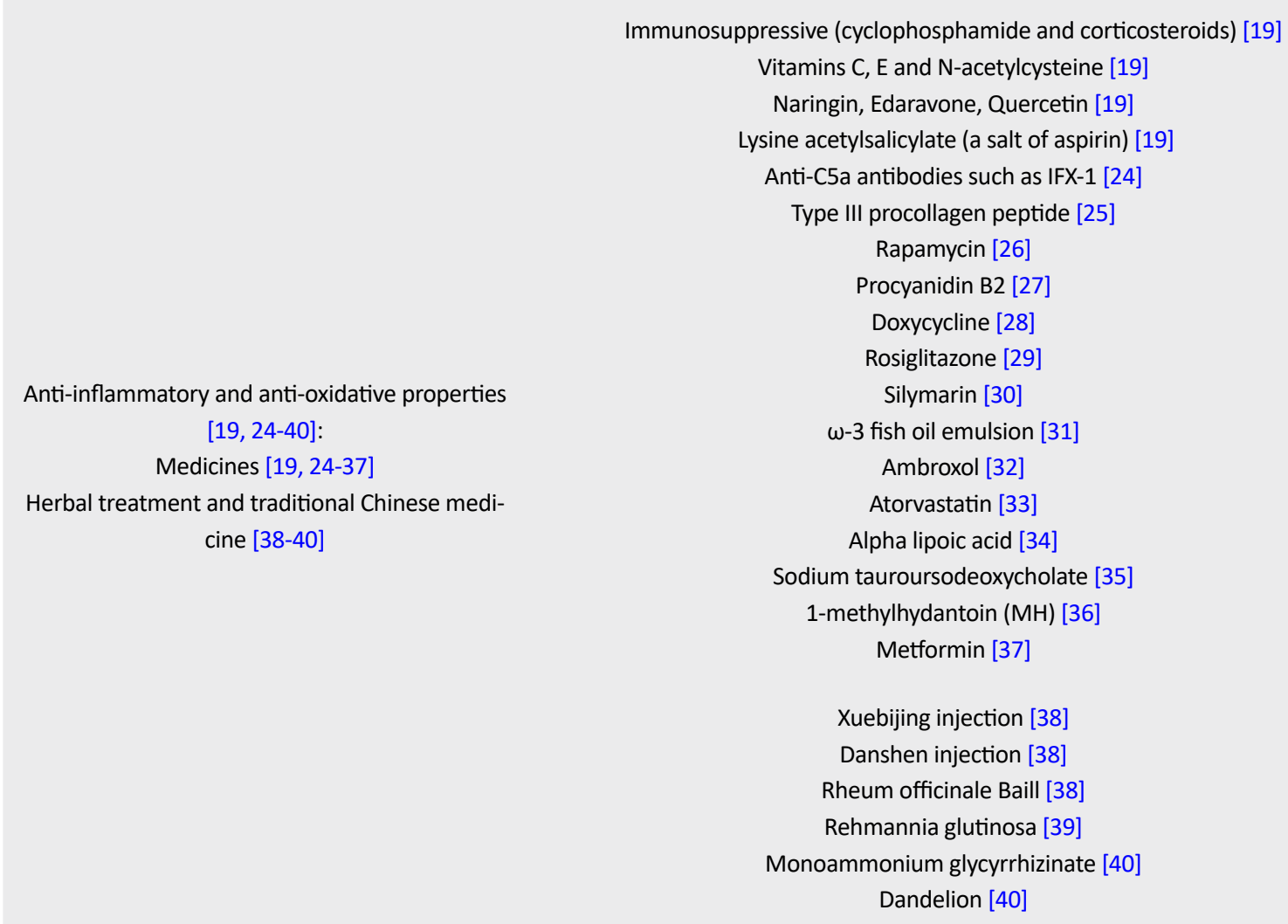

Procedures

Extracorporeal removal techniques (even in unknown hepatitis viral marker status) [41-44]

Hemodialysis

Hemoperfusion, charcoal hemoperfusion, and resin hemoperfusion

Hemodiafiltration and continuous venovenous hemofiltration

Blood purification

Surgical procedures [45-47]

Interventional strategy for pulmonary salvage such as one-lung circumvention

Lung transplantation with or without extracorporeal membrane oxygenation

Other procedures $[19,48,49]$

Lung radiotherapy

Mesenchymal stem cells

Whole lung lavage therapy 


\section{Conflict of interest}

The author declared no conflicts of interest.

\section{Acknowledgements}

The author would like to thank the management of Imam Khomeini Hospital, Urmia, Iran, for supporting this study.

1. APACHE II: Acute physiology and chronic health evaluation score

2. SOFA: Sequential organ failure assessment

\section{References}

[1] Cao ZX, Zhao Y, Gao J, Feng SY, Wu CP, Zhai YZ, et al Comparison of severity index and plasma paraquat concentration for predicting survival after paraquat poisoning: A meta-analysis. Medicine (Baltimore). 2020; 99(6):e19063. [DOI:10.1097/MD.0000000000019063]

[2] Wen X, Gibson CJ, Yang I, Buckley B, Goedken MJ, Richardson JR, et al. MDR1 transporter protects against paraquatinduced toxicity in human and mouse proximal tubule cells. Toxicol Sci. 2014; 141(2):475-83. [DOI:10.1093/toxsci/kfu141]

[3] Elenga N, Merlin C, Le Guern R, Kom-Tchameni R, Ducrot YM, Pradier M, et al. Clinical features and prognosis of paraquat poisoning in French Guiana: A review of 62 cases. Medicine (Baltimore). 2018; 97(15):e9621. [DOI:10.1097/ MD.0000000000009621]

[4] Buendía J A, Chavarriaga G J R, Zuluaga A F. Burden of paraquat poisoning in the department of Antioquia, Colombia. BMC Pharmacol Toxicol. 2019; 20(11). [DOI.org/10.1186/ s40360-019-0291-0]

[5] Delirrad M, Majidi M, Boushehri B. Clinical features and prognosis of paraquat poisoning: A review of 41 cases. Int J Clin Exp Med. 2015; 8(5):8122-8. [PMCID] [PMID]

[6] Jamshidi F, Fathi G, Davoodzadeh H. Investigation Paraquat Poisoning in Southwest of Iran - from Sign to Mortality and Morbidity. Arch Med Sadowej Kryminol. 2017; 67(1):35-45. [DOI:10.5114/amsik.2017.70336]

[7] Meng Z, Dong Y, Gao H, Yao D, Gong Y, Meng Q, et al. The effects of $\omega-3$ fish oil emulsion-based parenteral nutrition plus combination treatment for acute paraquat poisoning. J Int Med Res. 2019; 47(2):600-14. [DOI:10.1177/0300060518806110] [PMID] [PMCID]

[8] Wang X, Zhang M, Ma J, Zhang Y, Hong G, Sun F, et al Metabolic changes in paraquat poisoned patients and support vector machine model of discrimination. Biol Pharm Bull. 2015; 38(3):470-5. https://www.jstage.jst.go.jp/article/ bpb/38/3/38_b14-00781/_article/-char/ja/
[9] Song Y, Li C, Luo F, Tao Y. Clinical features and risk factors of acute kidney injury in children with acute paraquat intoxication. J Int Med Res. 2019; 47(9):4194-203 [DOI:10.1177/0300060519860032]

[10] Wang WJ, Cao ZX, Feng SY, Song YQ, Zhang SL, Bai WJ, et al. Platelet-lymphocyte ratio is not a prognostic predictor for acute paraquat-intoxicated patients: A retrospective analysis. Medicine (Baltimore). 2019; 98(20):e15702. [DOI:10.1097/ MD.0000000000015702]

[11] Kavousi-Gharbi S, Jalli R, Rasekhi-Kazerouni A, Habibagahi Z, Marashi SM. Discernment scheme for paraquat poisoning: A five-year experience in Shiraz, Iran. World J Exp Med. 2017; 7(1):31-39 [DOI:10.5493/wjem.v7.i1.31]

[12] Nelson LS, Howland MA, Lewin NA, Smith SW, Goldfrank LR, Hoffman RS, editors. Goldfrank's toxicologic emergencies, 11th ed. New York: McGraw-Hill; 2019. https://www. worldcat.org/title/goldfranks-toxicologic-emergencies/oclc /1085345149?referer=di\&ht=edition

[13] Liu ZN, Zhao M, Zheng Q, Zhao HY, Hou WJ, Bai SL. Inhibitory effects of rosiglitazone on paraquat-induced acute lung injury in rats. Acta Pharmacol Sin. 2013; 34(10):1317-24. [DOI:10.1038/aps.2013.65]

[14] Kervégant M, Merigot L, Glaizal M, Schmitt C, Tichadou L, de Haro L. Paraquat poisonings in France during the European ban: Experience of the Poison Control Center in Marseille. J Med Toxicol. 2013; 9(2):144-7. [DOI:10.1007/s13181-012-02836] [PMID] [PMCID]

[15] Kuan CM, Lin ST, Yen TH, Wang YL, Cheng CM. Paper-based diagnostic devices for clinical paraquat poisoning diagnosis. Biomicrofluidics. 2016; 10(3):034118. [DOI:10.1063/1.4953257]

[16] Hu X, Guo R, Chen X, Chen Y. Increased plasma prothrombin time is associated with poor prognosis in patients with paraquat poisoning. J Clin Lab Anal. 2018; 32(9):e22597. [DOI:10.1002/jcla.22597]

[17] Feng S, Gao J, Li Y. A retrospective analysis of leucocyte count as a strong predictor of survival for patients with acute paraquat poisoning. Plos One. 2018; 13(7): e0201200 [PMCID] [DOI:10.1371/journal.pone.0201200]

[18] Wu MR, Hsiao CY, Cheng CH, Liao FC, Chao CL, Chen $\mathrm{CY}$ and et al. Is endotracheal intubation a non-beneficial treatment in patients with respiratory failure due to paraquat poisoning? PLoS One. 2018; 13(3):e0195071. [DOI:10.1371/ journal.pone.0195071]

[19] Dorooshi G, Zolfaghari S, Eizadi-Mood N, Gheshlaghi F. A new treatment approach for acute paraquat poisoning. J Res Pharm Pract. 2018; 7(2):115-116. [DOI:10.4103/jrpp. JRPP_18_13]

[20] Junbo Z, Yongtao Y, Hongbo L, Fenshuang Z, Ruyun L, Chun'ai Y. Experimental study of sucralfate intervention for paraquat poisoning in rats. Environ Toxicol Pharmacol. 2017 53:57-63. [DOI:10.1016/j.etap.2017.03.023]

[21] Zhou Z, Zhang T, Sun X, Shi X. Milk gargle and activated carbon retention enema in the application of the treatment of acute paraquat poisoning. Zhonghua Lao Dong Wei Sheng Zhi Ye Bing Za Zhi. 2014;32(11):860-2. [PMID]

[22] Kumar P. Multani Mitti-Is it more than a placebo? J Pakistan Assoc Dermatologists. 2018; 29(3):345-8. 
[23] Wang W, Li J, Ma G, Li N, Wang P, Xiao Q, et al.Effect of rhubarb as the main composition of sequential treatment in patients with acute paraquat poisoning: a prospective clinical research. Zhonghua Wei Zhong Bing Ji Jiu Yi Xue. 2015, 27(4):254-8. [DOI:10.3760/cma.j.issn.2095-4352.2015.04.006] [PMID]

[24] Sun S, Jiang Y, Wang R, Liu C, Liu X, Song N, et al. Treatment of Paraquat-Induced Lung Injury with an Anti-C5a Antibody: Potential Clinical Application. Crit Care Med. 2018; 46(5):e419-e425. [DOI:10.1097/CCM.0000000000002950]

[25] Wang W, Hongna QI, Xiao Q, Gao X, Zhu B, LI W, et al. [Clinical value of type III procollagen peptide in sequeatial treatment with Rheum officinale BaiL as a predominant agent in a traditional Chinese medicine recipe in patients with acute paraquat poisoning (Chinese)]. Chinese J Emerg Med. 2017; 26(11):1240-1246. https://pesquisa.bvsalud.org/portal/resource/pt/wpr-664361

[26] Feng N, Bian Z, Zhang X, Wang C, Chen J. Rapamycin reduces mortality in acute-stage paraquat-induced toxicity in zebrafish. Singapore Med J. 2019; 60(5):241-246 [DOI:10.11622/smedj.2018132]

[27] Jiang Y, Yang W, Gui S. Procyanidin B2 protects rats from paraquat-induced acute lung injury by inhibiting NLRP3 inflammasome activation. Immunobiology. 2018; 223(10):555561. [DOI:10.1016/j.imbio.2018.07.001]

[28] Zhang F, Hu L, Wu YX, Fan L, Liu WT, Wang J and et al. Doxycycline alleviates paraquat-induced acute lung injury by inhibiting neutrophil-derived matrix metalloproteinase 9. Int Immunopharmacol. 2019; 72:243-251. [DOI:10.1016/j. intimp.2019.04.015]

[29] Zhang H, You L, Zhao M. Rosiglitazone attenuates paraquat-induced lung fibrosis in rats in a PPAR gammadependent manner. Eur J Pharmacol. 2019; 851:133-43. [DOI:10.1016/j.ejphar.2019.02.037] [PMID]

[30] Zakariaei Z. Silymarin as a Promising Potential Therapeutic Agent for Treatment of Patients with Paraquat Poisoning: An Issue that Merits Further Research. Adv J Emerg Med. 2019; 4(2):e16. [DOI:10.22114/ajem. v0i0.266] [PMID] [PMCID] [PMC]

[31] Tran K, Butcher R. Lipid formulations for patients requiring parenteral nutrition: A review of clinical effectiveness, cost-effectiveness, and guidelines - An Update [Internet]. Ottawa (ON): Canadian Agency for Drugs and Technologies in Health; 2019. [PMID]

[32] Wang J, Yu W, Wu N, Gitonga EN, Shen H. Efficacy of high-dose ambroxol for paraquat poisoning: A meta-analysis of randomized controlled trials. J Res Med Sci. 2020; 25:67. [DOI:10.4103/jrms.JRMS_484_19]

[33] Alizadeh-Tabrizi N, Malekinejad H, Varasteh S, Cheraghi $\mathrm{H}$. Atorvastatin protected from paraquat-induced cytotoxicity in alveolar macrophages via down-regulation of TLR-4. Environ Toxicol Pharmacol. 2017; 49:8-13. [DOI:10.1016/j. etap.2016.11.011]

[34] Pang L, Deng P, Liang YD, Qian JY, Wu LC, Yang LL and et al. Lipoic acid antagonizes paraquat-induced vascular endothelial dysfunction by suppressing mitochondrial reactive oxidative stress. Toxicol Res (Camb). 2019; 8(6):918-27. [DOI:10.1039/c9tx00186g]

[35] Omura T, Asari M, Yamamoto J, Oka K, Hoshina C, Maseda $\mathrm{C}$, et al. Sodium tauroursodeoxycholate prevents paraquat- induced cell death by suppressing endoplasmic reticulum stress responses in human lung epithelial A549 cells. Biochem Biophys Res Commun. 2013; 432(4):689-94. [DOI:10.1016/j. bbrc.2013.01.131]

[36] Liu B, Chen A, Lan J, Ren L, Wei Y, Gao L. Protective mechanism of 1-methylhydantoin against lung injury induced by paraquat poisoning. PLoS One. 2019 27;14(9):e0222521. [DOI:10.1371/journal.pone.0222521]

[37] Wu L, Cen Y, Feng M, Zhou Y, Tang H, Liao X, et al. Metformin activates the protective effects of the AMPK pathway in acute lung injury caused by paraquat poisoning. Oxid Med Cell Longev. 2019; 2019:1709718. [DOI:10.1155/2019/1709718]

[38] Hou J, Xiaotian WU. Observation on the effect of Xuebijing injection in treatment of acute paraquat poisoning. Chinese Journal of Primary Medicine and Pharmacy. 2013; (10):1483-4 http://wprim.whocc.org.cn/admin/article/articleDetail?W PRIMID $=434568 \&$ articleId $=434568$

[39] Ren L, Xu Y, Qin G, Liu C, Wang S. Effects of water extracts of Rehmannia glutinosa on antioxidant system of Nrf2 in paraquat-induced insulin resistance diabetic rat model. Exp Ther Med. 2017; 14(6):5847-5850. [DOI:10.3892/etm.2017.5302]

[40] Zhao Y, Jian XD. Clinical effect of compound monoammonium glycyrrhizinate combined with dandelion in treatment of acute paraquat poisoning. Zhonghua Lao Dong Wei Sheng Zhi Ye Bing Za Zhi. 2016; 34(7):535-7. [DOI:10.3760/cma.j.is sn.1001-9391.2016.07.015]

[41] Wang Y, Wu Y, Shen F, Liu B, Qian H, Yang H, et al. Clinical effect of haemoperfusion combined with continuous venoveno haemofiltration in treatment of paraquat poisoning: A Meta-analysis. Zhonghua Wei Zhong Bing Ji Jiu Yi Xue. 2019; 31(2):214-20. [DOI:10.3760/cma.j.issn.2095-4352.2019.02.018]

[42] Ji YS, Du KY, Guo WP. Effect of treatment with early blood purification combined with prednisone and cyclophosphamide for patients with acute paraquat poisoning. Zhonghua Lao Dong Wei Sheng Zhi Ye Bing Za Zhi. 2013; 31(5):388-9. [PMID]

[43] Zhao XH, Jiang JK, Lu YQ. Evaluation of efficacy of resin hemoperfusion in patients with acute 2,4-dinitrophenol poisoning by dynamic monitoring of plasma toxin concentration. J Zhejiang Univ Sci B. 2015; 16(8):720-6. https:/ / link.springer. com/article/10.1631/jzus.B1500101

[44] Marashi SM, Raji H, Nasri-Nasrabadi Z, Majidi M. Use of extracorporeal removal techniques in patients with paraquat toxicity and unknown hepatitis viral marker status. Ci Ji Yi Xue Za Zhi. 2016; 28(1):39. [DOI:10.1016/j.tcmj.2015.07.001]

[45] Jiang WZ, Chen YQ, Zhang YL, Zhang TT, Liu YM, Xu X. Lung transplantation in patients with paraquat poisoning: a case report and literature review. Zhonghua Lao Dong Wei Sheng Zhi Ye Bing Za Zhi. 2019 20; 37(4):292-6. [DOI:10.3760/ cma.j.issn.1001-9391.2019.04.013]

[46] Marashi SM, Raji H, Nasri-Nasrabadi Z, Majidi M, Vasheghani-Farahani M, Abbaspour A, et al. One lung circumvention, an interventional strategy for pulmonary salvage in acute paraquat poisoning: An evidence-based review. Tzu Chi Med J 2015; 27:99-101. https://www.sciencedirect. com/science/article/pii/S1016319015000580

[47] Tang X, Sun B, He H, Li H, Hu B, Qiu Z, et al. Successful extracorporeal membrane oxygenation therapy as a bridge to sequential bilateral lung transplantation for a patient after se- 
vere paraquat poisoning. Clin Toxicol (Phila). 2015; 53(9):90813. [DOI:10.3109/15563650.2015.1082183]

[48] Zhang H, Xiao B, Jiang L, Yao W, Shen H, Xiang X. Inhibition of mesenchymal stromal cells' chemotactic effect to ameliorate paraquat-induced pulmonary fibrosis. Toxicol Lett. 2019; 307:1-10. [DOI:10.1016/j.toxlet.2019.01.005]

[49] Kan B, Jian X, Zhang Z, Zhou Q, Wang J, Yu G, et al. Whole lung lavage therapy: Treatment for lung injury caused by paraquat poisoning. J Toxicol Environ Health Sci. 2014; 6(4):99102. [DOI:10.5897/JTEHS2014.0306] 